\title{
Seismic quiescence and activation anomalies from 2005 to 2008 beneath the Kanto district, central Honshu, Japan
}

\author{
Kei Katsumata ${ }^{1}$ and Shin'ichi Sakai ${ }^{2}$ \\ ${ }^{1}$ Institute of Seismology and Volcanology, Hokkaido University, North-10 West-8, Sapporo 060-0810, Japan \\ ${ }^{2}$ Earthquake Research Institute, University of Tokyo, 1-1-1 Yayoi, Bunkyo-ku, Tokyo 113-0032, Japan
}

(Received October 30, 2012; Revised May 25, 2013; Accepted June 21, 2013; Online published December 6, 2013)

\begin{abstract}
In the present study, an earthquake catalog is used that lists 1,197 earthquakes with $M \geq 3.9$. All of the earthquake waveforms were recorded by the Earthquake Research Institute, University of Tokyo. These waveforms have been manually re-examined, and hypocenters and magnitudes re-calculated. A detailed analysis of the re-determined earthquake catalog between 1996 and 2007, using a gridding technique (ZMAP), shows a pair of seismic quiescence and activation anomalies that start around the middle of 2005, and last about 30 months. The pair of quiescence and activation anomalies are located very close to each other, and the $Z$-values are +5.0 and -3.8 for a time window of $T_{w}=1.5$ years, using a sample size of $N=100$ earthquakes. The anomaly pair is not a coincidence as is confirmed by a numerical simulation with the assumption of random seismicity. One possible hypothesis is presented to explain the seismicity anomaly: a long-term slow slip event (LSSE) occurs on the upper boundary of the subducting Pacific plate, and the seismic quiescence and activation anomalies are caused by the Coulomb failure stress change associated with the LSSE.
\end{abstract}

Key words: Seismic quiescence, ZMAP, Kanto, slow slip event.

\section{Introduction}

A slow slip event (SSE) is a very slow faulting without the generation of high-frequency seismic waves. In general, the slip velocity is $\sim 1 \mathrm{~m} / \mathrm{s}$ for ordinary earthquakes and ranges from $\sim 1 \mathrm{~cm} /$ day to $\sim 1 \mathrm{~cm}$ /year for SSEs. In this study, we define a short-term SSE (SSSE) as an event with a slip velocity of 1 to $10 \mathrm{~cm} /$ day, and a long-term SSE (LSSE) as an event with a slip velocity of 1 to $10 \mathrm{~cm} /$ year. SSSEs with a duration time of several days are usually detected by a dense Global Positioning System (GPS) network: the Nankai subduction zone (Obara et al., 2004), the Boso (Ozawa et al., 2007), the Cascadia subduction zone (Dragert et al., 2001), the Cocos-Caribbean subduction zone (Outerbridge et al., 2010), and Kilauea volcano (Cervelli et al., 2002). Some SSSEs are accompanied by earthquake swarms. For example, Hirose et al. (2012) showed clear evidence of swarm activities near Boso Peninsula, central Japan, likely induced by stress perturbations caused by SSEs in the region. Moreover, these authors also demonstrated that the SSEs themselves could be triggered by static stress transfer from large earthquakes. On the other hand, LSSEs with a duration time of several years are also detected by a dense GPS network: the Bungo channel (Hirose and Obara, 2005) and the Tokai region (Ozawa et al., 2002) in the Nankai subduction zone of Japan, the south central Alaska subduction zone (Ohta et al., 2006), the Guerrero seismic gap of the Mexican subduction zone

Copyright (C) The Society of Geomagnetism and Earth, Planetary and Space Sciences (SGEPSS); The Seismological Society of Japan; The Volcanological Society of Japan; The Geodetic Society of Japan; The Japanese Society for Planetary Sciences; TERRAPUB.

doi:10.5047/eps.2013.06.006
(Yoshioka et al., 2004), and the Manawatu region of North Island, New Zealand (Wallace and Beavan, 2006).

Not only GPS data but also a temporal change in seismicity rate might enable us to detect SSEs. For example, seismicity rate changes were observed associated with a large LSSE from 2000 to 2005 in the Tokai district (Matsumura, 2006; Kobayashi and Hashimoto, 2007). Based on a rate- and state-dependent friction law, Dieterich et al. (2000) developed a method to calculate the stressing rate by using earthquake rate changes. Toda and Matsumura (2006) applied Dieterich's method to the seismicity data in the Tokai district, and found that the seismicity rate changes were well explained by the stress perturbation caused by the Tokai LSSE. Llenos and McGuire (2011) also presented an inversion method to detect the variation in stressing rate by using the earthquake occurrence rate.

However, there are important shortcomings for investigating precise and reliable temporal changes in long-term seismicity. The homogeneity of an earthquake catalog is critical for the analysis and, in general, most catalogs are not homogeneous temporally and spatially (Habermann, 1987, 1991). For this reason, a homogeneous earthquake catalog needs to be constructed prior to such an analysis. Apparent changes in seismicity rates are easily produced by artificial effects, including the deployment of new seismograph stations, the closing of old seismograph stations, and changes to the seismograph, waveform-recording system, and magnitude estimation algorithm (Habermann and Creamer, 1994; Zuniga and Wiemer, 1999).

The purpose of this study is to detect seismicity rate changes in the Kanto district, central Honshu, Japan, from an analysis of earthquake catalog data, and to propose a 


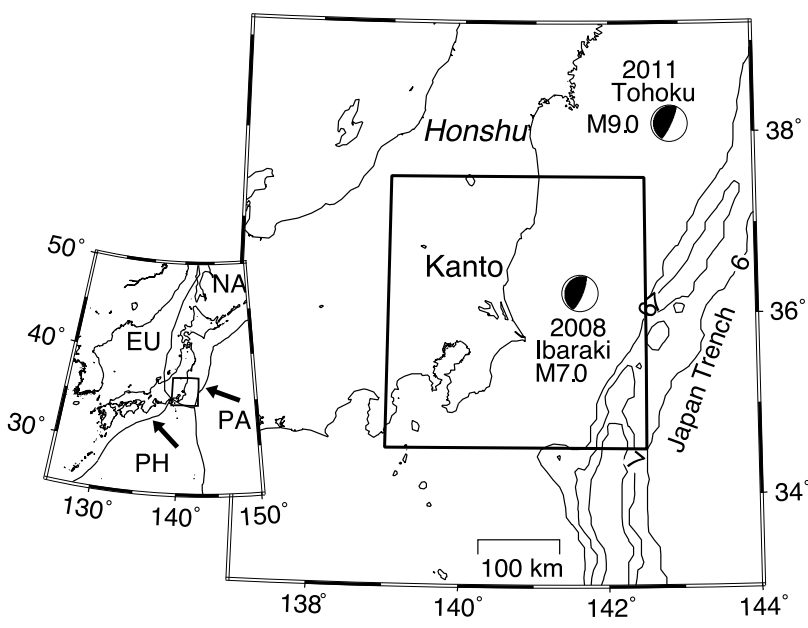

Fig. 1. Honshu subduction zone. The rectangle with the bold solid line indicates the study area. The focal mechanism is shown for the 2008 Ibaraki-oki earthquake (M 7.0) and the 2011 Tohoku-oki earthquake (M 9.0) Six to eight kilometer contours at the Japan Trench show the ocean-bottom topography. The inset shows plate boundaries: the Eurasian (EU), Pacific (PA), North American (NA) and Philippine Sea $(\mathrm{PH})$ plates. Arrows indicate the direction of plate motion relative to the EU plate.

slow-slip model to explain these seismicity changes. First, all waveform data are carefully re-examined and hypocenters and magnitudes are re-determined in order to obtain a reliable earthquake catalog that is spatially and temporally homogeneous. Second, the temporal change in seismicity is then defined quantitatively using an algorithm in the program ZMAP (Wiemer and Wyss, 1994), and, finally, we present a discussion regarding an LSSE, which seems to be a possible model to explain the seismicity rate changes detected in this study.

The tectonic setting of the study area is as follows. The Kanto district is located on the Okhotsk Sea plate or the North American (NA) plate, bordered by the Pacific (PA), the Philippine Sea (PH), and the Eurasia plate (Fig. 1). The Kanto district is unusual in that the two plates overlap each other: the PH plate subducts beneath the NA plate from the south of Kanto district, and the PA plate subducts beneath the PH plate from the east of Kanto district. The PH plate moves northwest at a velocity of approximately $30 \mathrm{~mm} /$ year relative to the NA plate, and the PA plate moves west-northwest at a velocity of approximately 76 $\mathrm{mm} /$ year relative to the NA plate (Seno et al., 1993; Seno and Sakurai, 1996). Recently, a large earthquake occurred at 1:45 a.m. on 8 May, 2008 (Japan Standard Time) off the pacific coast of Ibaraki Prefecture in the Kanto district (Fig. 1). The earthquake is referred to as the 2008 Ibaraki-oki earthquake, in the present paper. The location of the hypocenter, determined by the Japan Meteorological Agency (JMA), was $36.22^{\circ} \mathrm{N}, 141.61^{\circ} \mathrm{E}$ and $51 \mathrm{~km}$ in depth, and $M$ 7.0. According to the CMT solution determined by JMA, the focal mechanism was a low-angle thrust type $\left(\right.$ strike $=209^{\circ}, \operatorname{dip}=19^{\circ}$, rake $\left.=94^{\circ}\right)$ and the seismic moment was $M_{0}=1.7 \times 10^{19} \mathrm{~N} \mathrm{~m}\left(M_{\mathrm{w}}=6.8\right)$. This event was a typical subduction zone earthquake on the interface between the subducting PA and the overlying NA plates. The 2008 Ibaraki-oki earthquake ruptured the same asperities as those ruptured by the Ibaraki-oki earthquake in 1982 (Nagoya University, 2008). In this area, $M \sim 7$ earthquakes have occurred six times since 1896 with an average recurrence time of $22.5 \pm 4.0$ years (Matsumura, 2010). Coseismic and post-seismic slips were observed clearly by the GPS Earth Observation Network (GEONET) (Suito et al., 2011). Two foreshocks larger than $M 6.0$ occurred within one hour before the main shock, whereas no pre-slip was detected by GEONET.

\section{Data}

The most important requirement for an earthquake rate analysis is the use of a homogeneous earthquake catalog. Recently, many new seismographic stations have been installed in the Kanto region. At present, the network maintained by the Earthquake Research Institute, University of Tokyo (ERI), consists of about 660 short-period seismograph stations, including Hi-net (the high-sensitivity seismographic network) and stations maintained by JMA. All the waveform data are converted to a digital form at 100 $\mathrm{Hz}$, sent to the ERI via a communication satellite, exclusive telephone lines, or an internet connection, and stored on both hard disks and 8-mm video tapes.

In the present study, earthquakes were selected from the ERI catalog that satisfied the following conditions: (1) they occurred between 1 January, 1996, and 31 December, 2007; (2) they were located in the study area shown in Fig. 1; and (3) they had magnitudes of $M \geq 3.3$. Approximately 160,000 events satisfied conditions (1) and (2). Of these, 3,138 events satisfied the condition (3), and the waveforms associated with these events were re-examined.

The earthquakes in the study area were relocated using stations which were deployed before 1996, and where there has been no change in the observation conditions up to the present (Fig. 2). Data from any station installed after 1996 have not been used in this process, in order to preserve the homogeneity of the earthquake catalog. The arrival times of $P$-waves are determined from the vertical component at all 22 stations in Fig. 2(a). The arrival times of $S$-waves are determined from the horizontal component at the 4 stations indicated by the closed circles in Fig. 2(a). The hypocenters are then determined from the arrival time data using the program HYPOMH, which is based on a simple algorithm to find the maximum likelihood solution using a Bayesian approach (Hirata and Matsu'ura, 1987). The one-dimensional $P$-wave velocity model shown in Fig. 2(b) is used; this is the same as that used for the hypocenter calculations in the ERI data processing system. The $S$-wave velocity is determined by assuming that $V_{p} / V_{s}=\sqrt{3}$, where $V_{p}$ and $V_{s}$ are the $P$ - and $S$-wave velocities, respectively. This is equivalent to assuming that the Poisson's ratio is 0.25 . A value of 0.25 applies mainly to crustal structures, whereas values in the mantle are typically higher (approximately 0.28). In general, this ratio varies with changes in material composition. The maximum amplitudes are measured on the vertical component at the 7 stations indicated by the closed circles and closed triangles in Fig. 2(a). The magnitude $M_{i}$ is calculated at each station using the equation:

$$
0.85 M_{i}-2.50=\log A_{v}+1.73 \log r
$$



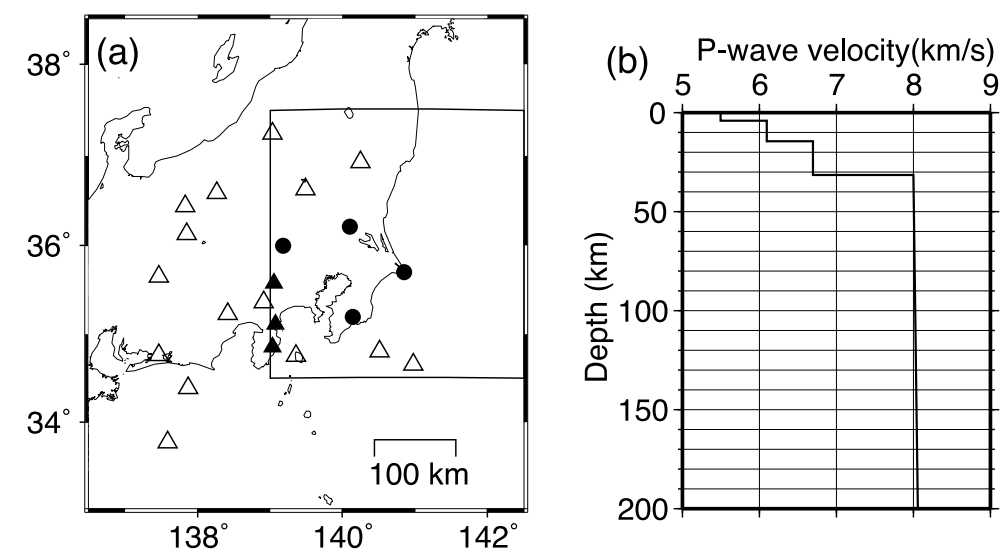

Fig. 2. (a) Seismographic stations used in the relocation of hypocenters. The rectangle with the bold solid line indicates the study area. Arrival times of $P$-waves only at the stations indicated by open and closed triangles are used. Arrival times of both $P$ - and $S$-waves are used at the stations indicated by closed circles. Magnitudes are calculated from the maximum amplitude at the stations indicated by closed circles and closed triangles. (b) $P$-wave velocity structure used for hypocenter location in the study area, which is the same as that used for the hypocenter calculation in the ERI data processing system. Poisson's ratio is assumed to be 0.25 in each layer.

(a) not-declustered
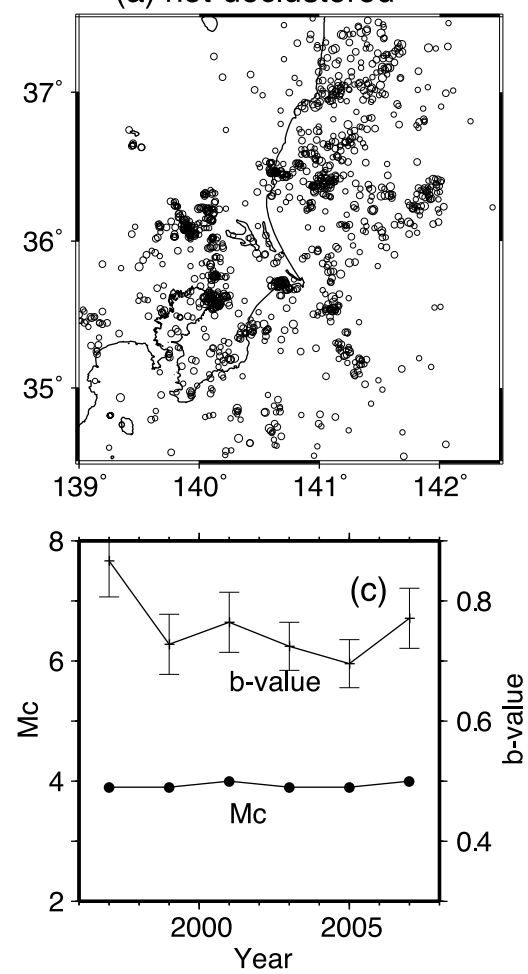

(b) not-declustered
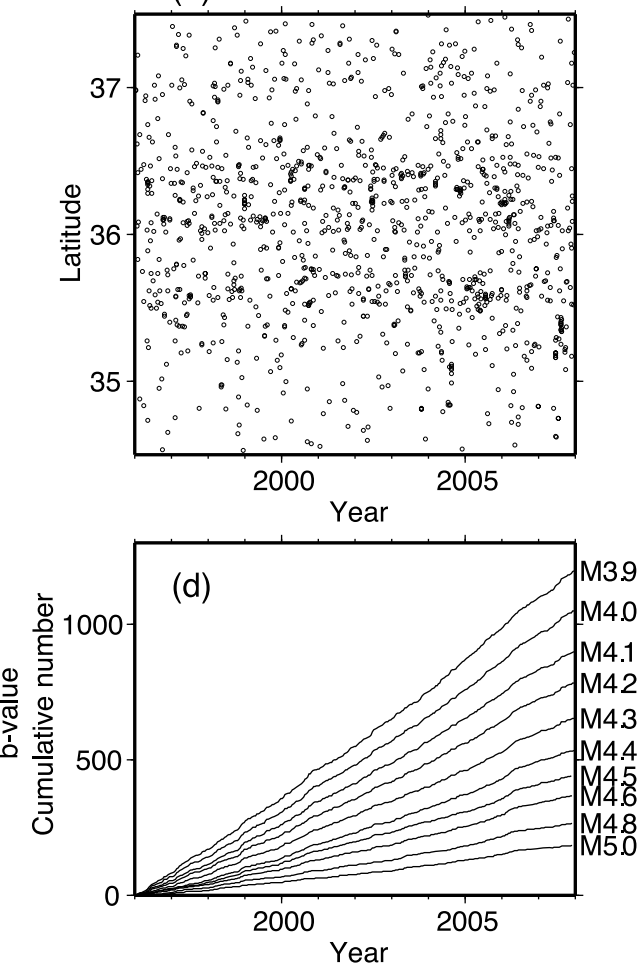

Fig. 3. (a) Epicenters of earthquakes used in this study (1 January, 1996-31 December, 2007, $M \geq 3.9,0 \leq$ Depth (km) $\leq 90$ ). This earthquake catalog includes clustered events such as aftershocks and earthquake swarms. (b) Space-time plot of earthquakes shown in (a). (c) Temporal change in $b$-value and $M_{\mathrm{c}}$ in the entire study area. $M_{\mathrm{c}}$ is the minimum magnitude that satisfies the G-R relation. The time window is two years long. For example, a value plotted for 1997 is calculated from earthquakes between 1996 and 1998. (d) Cumulative number of earthquakes as a function of time. Magnitude labels on each curve indicate the lower threshold of magnitude. For example, the curve with a label of $M 4.0$ represents the cumulative number of earthquakes with $M \geq 4.0$.

where $A_{v}$ is the maximum amplitude in $\mathrm{cm} / \mathrm{s}$ and $r$ is an epicentral distance in $\mathrm{km}$ (Watanabe, 1971). The magnitude of an earthquake is obtained by averaging the $M_{i}$ values for the 7 stations where the maximum amplitudes are measured.

1,197 earthquakes were then selected which satisfied the following conditions: (1) the epicenters were located in the study area excluding the inland crust; (2) the depth was equal to, or shallower than, $90 \mathrm{~km}$; and (3) the magnitude was equal to, or larger than, 3.9. These 1,197 earth- quakes then formed the basis of this analysis (Figs. 3(a) and 3(b)). In this study, clustered events, such as aftershocks and earthquake swarms, are not removed, because the declustering of an earthquake catalog is a non-unique procedure with well-known shortcomings (Zhuang et al., 2002). We show in the discussion that a declustering process has no effect on the results obtained in this study. The number of earthquakes versus magnitude is then examined for the catalog to estimate the magnitude of completeness, 


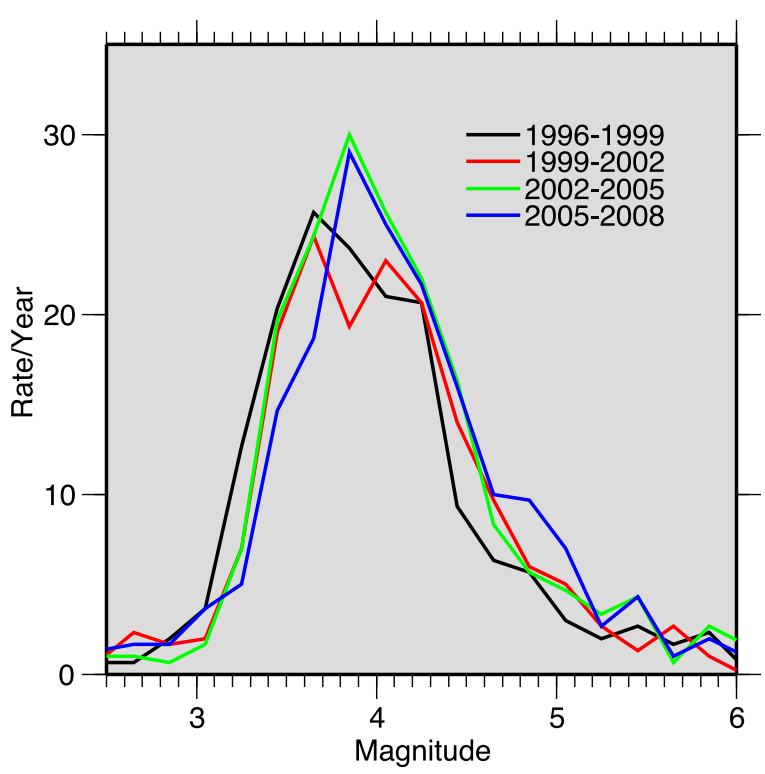

Fig. 4. Histogram of seismicity rate for three-year periods.

$M_{\mathrm{c}}$. In this study, $M_{\mathrm{c}}$ is defined as the magnitude at which at least $90 \%$ of the frequency-magnitude distribution can be modeled using a power law (Wiemer and Wyss, 2000). The results indicate that almost all earthquakes with $M \geq 3.9$ can be located without fail, that is, $M_{\mathrm{c}}=3.9$, and there is no temporal change in $M_{\mathrm{c}}$ (Fig. 3(c)). Figure 3(d) plots the cumulative number of events vs. time, and it can be seen that the reporting in this catalog does not change with time over the entire magnitude range. In addition, as shown in Fig. 4, there is no magnitude shift or stretch during this period. The seismicity rate is almost constant for all magnitude bands and all time windows in the entire study area.

\section{Analysis \\ 3.1 ZMAP}

A gridding technique (ZMAP, Wiemer and Wyss, 1994) is used to produce an image of the significance of rate changes in space and time. Key parameters for the ZMAP analysis are listed in Table 1 . Since the detailed procedure to calculate the $Z$-values were described by Katsumata (2011), we only show a summary of the analysis in this study. The study area is divided by a grid from $34.5^{\circ} \mathrm{N}$ to $37.5^{\circ} \mathrm{N}$ and from $139.0^{\circ} \mathrm{E}$ to $142.5^{\circ} \mathrm{E}$, with an interval of $0.05^{\circ}$. Thus, the total number of nodes is $61 \times 71=$ 4,331. A circle is drawn around each node and its radius $r$ is increased until it includes a total number of epicenters of $N=100$. The radius $r$ indicates the spatial resolution. The cumulative number of events vs. time is plotted for each node, starting at a time $t_{0}$ (1 January, 1996) and ending at a time $t_{e}$ (31 December, 2007). A time window is placed, starting at $T_{s}$ and ending at $T_{s}+T_{w}$, where $t_{0} \leq T_{s} \leq T_{s}+T_{w} \leq t_{e}$. A $T_{w}$ value of 1.5 years is used here, and $T_{s}$ is moved forward in steps of 0.04 years $(\sim 14$ days). For each window position, the $Z$-value is calculated, generating the function LTA defined by Wiemer and Wyss (1994), which measures the significance of the difference between the mean seismicity rate $R_{w}$ within the window $T_{w}$, and the background rate $R_{\mathrm{bg}}$ which is defined here as the mean rate in the time period between $t_{0}$ and $t_{e}$, exclud$\operatorname{ing} T_{w}$. The $Z$-value is defined as:

$$
Z=\left(R_{\mathrm{bg}}-R_{w}\right) /\left(S_{\mathrm{bg}} / n_{\mathrm{bg}}+S_{w} / n_{w}\right)^{1 / 2}
$$

where $S$ and $n$ are the variance and number of samples, respectively.

The Z-maps shown in Fig. 5 present time slices for the re-examined earthquake catalog every year between $T_{s}=$ 2001 and 2006. Note that clustered events, such as aftershocks and earthquake swarms, are not removed. For each time slice, only grid points having a resolution circle with $r \leq 60 \mathrm{~km}$ are selected and colored; these define the effective grid points. The number of effective grid points is 1,977 for each time slice, and since there are 262 time slices, the total number of effective grid points, where $Z$-values are calculated, is 517,974 . Figure 6(a) shows a histogram of $Z$-values calculated at all the nodes; it indicates that few $Z$-values larger than +3.0 , or smaller than -3.0 , are observed in this case. Positive and negative $Z$-values indicate that the seismicity rate is lower, and higher, than the background rate, respectively. Among these, only 6 nodes have $Z$-values equal to, or larger than, +5.0 , and only 1 node has a $Z$-value equal to, or smaller than, -3.8 after January 2001 (Table 2).

Based on the location and starting time, the above 7 nodes are divided into three anomalies: Anomaly 1 consists of the node No. 1, Anomaly 2 consists of the nodes from No. 2 to 4 , and Anomaly 3 consists of the nodes from No. 5 to 7. Node No. 1 is located at $\left(36.05^{\circ} \mathrm{N}, 140.35^{\circ} \mathrm{E}\right)$, the start time of Anomaly 1 is 2006.00 , and its $Z$-value is -3.8 , which is the smallest value among the $517,974 \mathrm{Z}$ values obtained in the present analysis. Nodes No. 2 to 4 are located at $\left(35.90^{\circ} \mathrm{N}, 140.90^{\circ} \mathrm{E}\right)$. The start time of Anomaly 2 is 2005.60 , obtained by taking the average $T_{s}$ for nodes No. 2 to 4 , and its $Z$-value is +5.0 . The parameters for Anomaly 3 are represented by the values obtained at node No. 6: the center of the anomalous area is $\left(36.45^{\circ} \mathrm{N}\right.$, $141.90^{\circ} \mathrm{E}$ ), the start time is 2006.48 , and the $Z$-value is +5.2. The obtained parameters of the three anomalies are summarized in Table 3.

\subsection{False alarms}

Another method of displaying $Z$-value anomalies that could be false alarms is by the use of alarm cubes (Wiemer, 1996; Wyss et al., 1996; Wyss and Martirosyan, 1998). In these three-dimensional figures (Fig. 6(b)), the horizontal axes are the spatial coordinates in the study area and the vertical axis is time. Anomalies are defined as instances of $Z$-values larger than +5.0 , or smaller than -3.8 , at any node and at any time. Figure 6(b) illustrates visually that the results are reliable. As listed in Table 2, the alarm cube includes three outstanding anomalies starting around 2006. Anomaly 1 is the only anomaly with a $Z$-value smaller than -3.8 , all time period in this catalog. On the other hand, there are some nodes with a $Z$-value larger than +5.0 between 1996 and 2001, suggesting that similar anomalies with $Z$-values larger than +5.0 occur frequently. As is mentioned in Section 3.5, however, the probability that Anomalies 1 to 3 occur at close locations in space and time, as a coincidence, is very low. 
Table 1. Characteristic parameters for ZMAP in this study.

\begin{tabular}{ll}
\hline Study area & $139.0-142.5^{\circ} \mathrm{E}, 34.5-37.5^{\circ} \mathrm{N}$ \\
Time interval of earthquake catalog & 1 January $1996-31$ December 2007 \\
Time length of earthquake catalog (days) & 4383 \\
Magnitude range & $M \geq 3.9$ \\
Depth range of hypocenters $(\mathrm{km})$ & $0-90$ \\
The total number of earthquakes & 1197 \\
Grid interval & $0.05^{\circ} \times 0.05^{\circ}$ \\
Radius of resolution circles $(\mathrm{km})$ & $r \leq 60$ \\
The number of effective grids & 1977 \\
Length of bin (days) & 14 \\
Time step of $T_{s}$ (years) & 0.04 \\
The number of time steps & 262 \\
The number of earthquakes for each grid & 100 \\
$T_{w}$ (years) & 1.5 \\
\hline
\end{tabular}

Table 2. Small and large $Z$-values obtained by ZMAP analysis ${ }^{\mathrm{a}}$.

\begin{tabular}{clllll}
\hline No. & Lon. & Lat. & $T_{s}$ & $r$ & $Z$ \\
\hline 1 & 140.35 & 36.05 & 2006.00 & 35.8 & -3.8 \\
2 & 140.90 & 35.90 & 2005.56 & 36.4 & +5.0 \\
3 & 140.90 & 35.90 & 2005.60 & 36.4 & +5.0 \\
4 & 140.90 & 35.90 & 2005.64 & 36.4 & +5.0 \\
5 & 141.85 & 36.45 & 2006.48 & 51.3 & +5.1 \\
6 & 141.90 & 36.45 & 2006.48 & 53.2 & +5.2 \\
7 & 141.95 & 36.45 & 2006.48 & 56.9 & +5.2 \\
\hline a $r:$ radius of resolution circle in km. $T_{s}:$ the time in decimal year that the \\
seismic quiescence or the activation started between 1 January, 2001, and 31 \\
December, 2007. Z: Z $Z$-value, positive and negative values indicate decrease \\
and increase in seismicity rate, respectively.
\end{tabular}

Table 3. Parameters of seismic quiescence and activation anomalies associated with an LSSE.

\begin{tabular}{|c|c|c|c|c|c|c|c|c|}
\hline $\begin{array}{l}\text { Anomaly } \\
\text { No. }\end{array}$ & Lon. & Lat. & $\begin{array}{l}\text { Radius of resolution } \\
\text { circle } r(\mathrm{~km})\end{array}$ & $\begin{array}{l}\text { Sample } \\
\text { size } N\end{array}$ & $\begin{array}{l}\text { Window length } \\
T_{w} \text { (years) }\end{array}$ & $\begin{array}{l}\text { Relative } \\
\text { significance } Z\end{array}$ & $\begin{array}{l}\text { Start date } \\
T_{s} \text { (decimal years) }\end{array}$ & $\begin{array}{l}\text { Duration } \\
\text { (years) }^{\mathrm{a}}\end{array}$ \\
\hline 1 & 140.35 & 36.05 & 36 & 100 & 1.5 & -3.8 & 2006.00 & 2.3 \\
\hline 2 & 140.90 & 35.90 & 36 & 100 & 1.5 & +5.0 & 2005.60 & 2.7 \\
\hline 3 & 141.90 & 36.45 & 53 & 100 & 1.5 & +5.2 & 2006.48 & 1.9 \\
\hline
\end{tabular}

a Duration is defined as $T_{\text {main }}-T_{s}$, where $T_{\text {main }}$ is the origin time of the 2008 Ibaraki-oki earthquake $(M 7.0)$.

\subsection{Anomaly volumes}

To verify the reliability of the seismicity rate changes determined in the previous section, the cumulative number of earthquakes is examined as a function of time in the volumes of Anomalies 1 to 3 . The cumulative curves in Fig. 7 indicate seismicity rate changes at specific nodes in the cases of Anomalies 1 to 3 . The statistical functions, LTA, displayed in Fig. 7 are the $Z$-values calculated by the method described in Section 3.1. Since a peak in $Z$-value corresponds to the time when the change in the seismicity rate starts, the clear anomalies are found to start around 2006 and persist until the end of 2007. The seismicity rate clearly increases from 7.0 to 14.7 events/year (a rise of $110 \%$ ) for Anomaly 1, decreases from 9.3 to 4.2 events/year (a drop of 55\%) for Anomaly 2, and decreases from 9.3 to 1.0 events/year (a drop of 89\%) for Anomaly 3.

The earthquake catalog we have analyzed includes clustered events (e.g., aftershocks, earthquake swarms), thus the increase in the seismicity rate in the area of Anomaly 1 might be caused by clustered events. An earthquake with M 6.0 occurred on 23 July, 2005 (Fig. 7(a)), which is the largest event around Anomaly 1 between 2005 and 2008. The main shock was followed by four aftershocks with $M$ 3.7-4.6 within three days. Furthermore, no earthquake swarm was observed in and around Anomaly 1, and no earthquake with $M 7.0$ or larger occurred between 2004 and 2008 within $200 \mathrm{~km}$ from Anomaly 1. Therefore, we conclude that it is unlikely that clustered events are the main reason for the increase in seismicity rate which continued for more than one year.

Epicenters within Anomaly 3 are located near the asperity ruptured by the 2008 Ibaraki-oki main shock. Epicenters within Anomalies 1 and 2 are located west of the focal area of the 2008 Ibaraki-oki main shock (Fig. 7(a)). The depth of hypocenters is systematically increasing westward from Anomalies 3 to 1 along the subducting Pacific plate (Fig. 7(b)). 



Fig. 5. Time slices of $Z$-value distribution using the re-examined non-declustered catalog. The time window starts at $T_{s}$ and ends at $T_{s}+T_{w}$, where $T_{w}=1.5$ years. Only grid points with a radius of the resolution circle smaller than $60 \mathrm{~km}$ are selected. The number of such points is 1977 . A red color (positive $Z$-value) and blue color (negative $Z$-value) represents a decrease and increase in the seismicity rate, respectively. Two alarms with $Z \geq+5.0$ are detected: $\mathrm{A} 2$ and $\mathrm{A} 3$, and one alarm with $Z \leq-3.8$ is detected: A1 (see text). A closed star and gray dots indicate the epicenter of the 2008 Ibaraki-oki earthquake (M 7.0) and its aftershocks determined by JMA, respectively.
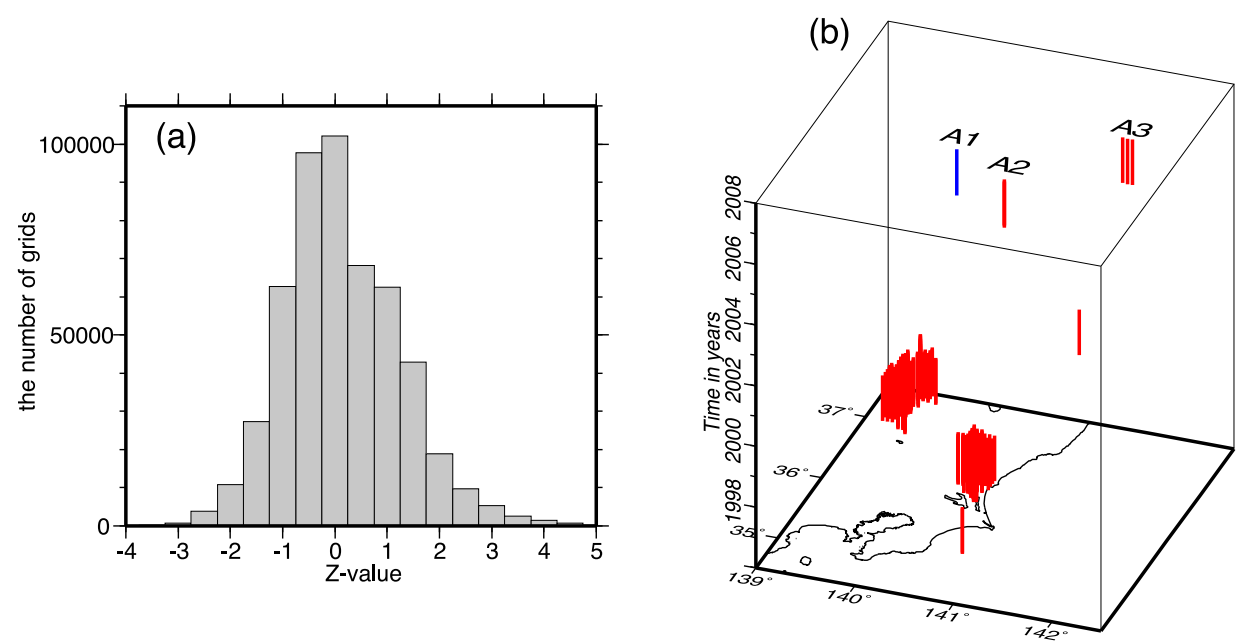

Fig. 6. (a) $Z$-value distribution. The number of effective grid points is 517,974 in the alarm cube for the ERI non-declustered catalog. (b) Alarm cube. Vertical bold lines with a time length of 1.5 years indicate alarms with $Z \geq+5.0$ (red, quiescence) or $Z \leq-3.8$ (blue, activation).

\subsection{Apparent seismicity changes due to the magnitude shift}

Since an apparent seismicity change is often due to manmade causes, the $Z$-value anomalies found in the present study should be carefully examined. In particular, magnitude shifts and stretches critically affect the results (Wiemer and Wyss, 1994). Figure 8 shows the magnitude signatures for the entire study area for two time windows, before and after 2006.0 (1 January, 2006), which is around the start time of the three anomalies. The $b$-values in the magnitudefrequency plot are 0.79 and 0.86 before, and after, the start time, respectively, which are almost identical (Fig. 8(a)). In addition, the seismicity rate shows no change for $M \geq 3.9$ (Fig. 8(b, c)). From this, it can be concluded that there is no significant magnitude shift or stretch in the entire study area before, or after, the start time of the $Z$-value anomalies.

Figure 9 shows the magnitude signatures for Anomalies 1 to 3 for two time windows, before, and after, the start time of the anomalies. In these plots, all earthquakes with $M \geq$ 3.3 are considered. For Anomaly 1, the $b$-value increases from 0.67 to 1.2 . To estimate the statistical significance, we estimate the probability that two samples may come from 

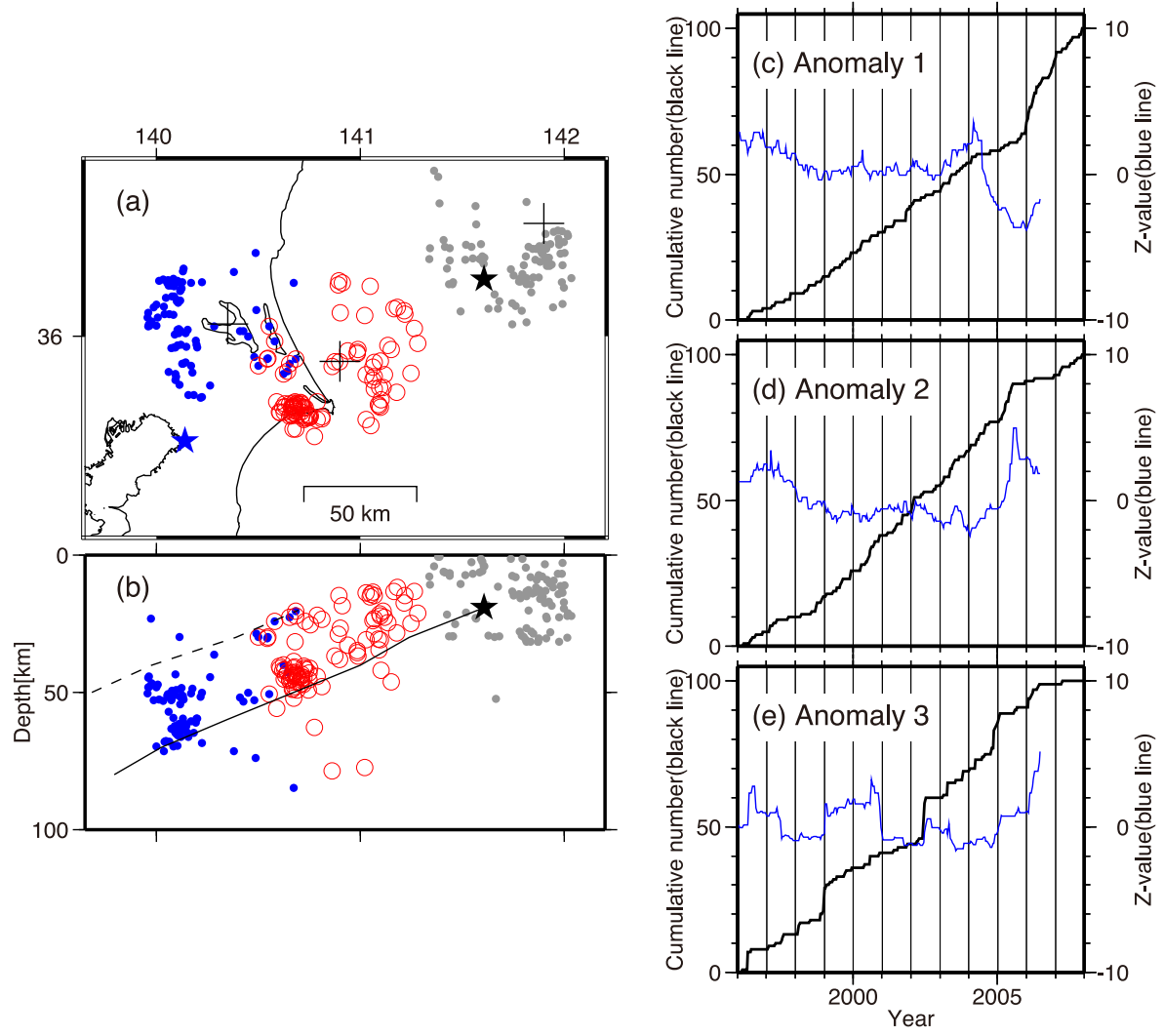

Fig. 7. Cumulative number and Z-value plots for anomalous areas detected in Fig. 5. (a) Distribution of epicenters in the volumes of Anomaly 1 (A1, blue dots), Anomaly 2 (A2, open red circles), and Anomaly 3 (A3, gray dots). Plusses denote the centers of resolution circle in each area. A black star indicates the epicenter of the 2008 Ibaraki-oki earthquake (M 7.0). A blue star indicates the epicenter of an earthquake $(M 6.0)$ which occurred on 23 July, 2005. (b) Vertical cross-section of the east-west direction in Fig. 7(a) with the upper boundary of the Pacific plate (solid line) and the Philippine Sea plate (broken line). (c), (d) and (e) show the cumulative number (black line) and the $Z$-value (blue line) in the volumes of Anomalies 1 to 3 .

the same population by a test (Utsu, 1999). In the case of Anomaly 1 , the probability $P=2 \%$. For Anomaly 2, the $b$-value decreases from 0.85 to 0.65 , and $P=22 \%$. For Anomaly 3 , the $b$-value decreases from 0.72 to 0.43 , and $P=8 \%$. Based on Utsu's test, there is no significant change in the $b$-value statistically if a significance level of $99 \%$ is adopted. Thus, it is unlikely that there is a manmade shift in the magnitude-frequency distribution because there is no change in the detection capability, or $b$-value, over the entire study area, as shown in Fig. 8. However, it does not seem to be a coincidence that the $b$-value increases in the activated area (Anomaly 1), and decreases in the quiescence areas (Anomalies 2 and 3), which is consistent with the observation that the $b$-value decreased from 0.91 to 0.61 in the quiescence area prior to the 2003 Tokachi-oki earthquake $\left(M_{\mathrm{w}}=8.3\right)$ (Katsumata, 2011).

\subsection{Statistical significance of the results}

In order to estimate the statistical significance of the $Z$ value anomalies detected in this study, synthetic seismicity data is generated, and $Z$-value matrices and the distributions of maximum $Z$-values, $Z_{\max }$, and minimum $Z$-values, $Z_{\text {min }}$, are determined. The method of the numerical simulation has been explained by Katsumata (2011) in detail. In this study, the procedure is repeated 12,500 times and $Z_{\max }$ and $Z_{\min }$ are evaluated for each repetition.

In Fig. $10, Z_{\max }$ is seen to range from 5 to 11 and there are four discrete peaks around $Z_{\max }=10.2,7.8,6.4$, and
5.2. The four peaks are mainly associated with the number of earthquakes within the time window $T_{w}=1.5$ years. If no earthquake is observed within $T_{w}=1.5$ years, the $Z$-value is expected to be $\sim 10$. If one earthquake is observed, $Z \sim 8$. If two and three earthquakes are observed, $Z \sim 6$ and $Z \sim 5$, respectively. Based on this distribution, the probability of $Z_{\max }$ being 5.0 or larger is approximately $100 \%$. Therefore, neither of the quiescence Anomalies 2 and 3 detected in this study is a rare phenomenon. $Z_{\min }$ is seen to range from -5 to -3 and the average is -3.65 . Based on this distribution, the probability of $Z_{\min }$ being -3.8 , or smaller, is $31 \%$. Therefore, the activation Anomaly 1 detected in this study is not a rare phenomenon, neither.

However, it may still be considered unlikely that three such anomalies would occur at almost the same time and location. In particular, the onset times of Anomalies 1 and 2 are 2006.0 and 2005.6, respectively, which is a difference in time of $d t=0.4$ years. The location of Anomalies 1 and 2 are $\left(36.05^{\circ} \mathrm{N}, 140.35^{\circ} \mathrm{E}\right)$ and $\left(35.90^{\circ} \mathrm{N}, 140.90^{\circ} \mathrm{E}\right)$, respectively, which is a difference of latitude $d$ lat $=0.15^{\circ}$ and a difference of longitude $d$ lon $=0.55^{\circ}$. We find that the probability that two such anomalies, as closely located in time and space, would occur by chance is smaller than $0.008 \%$; that is, there is no pair of quiescence and activation that simultaneously satisfies the three conditions, $d t \leq 0.4$ years, $d$ lat $\leq 0.15^{\circ}$, and $d$ lon $\leq 0.55^{\circ}$, in 12,500 times. 

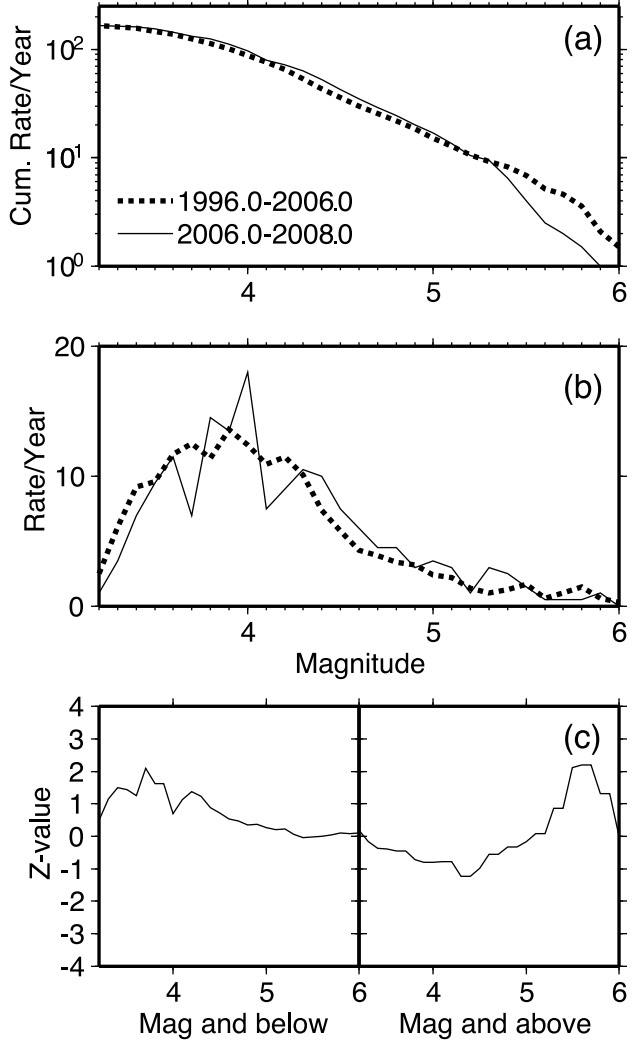

Fig. 8. Magnitude signatures for the entire study area. Broken and bold lines indicate the normal period (1996.0-2006.0) and the anomalous period (2006.0-2008.0), respectively. (a) Plot of magnitude vs. cumulative number. (b) Plot of magnitude vs. frequency. (c) Plot of magnitude vs. $Z$-value. The label "Mag and below" on the horizontal axis in (c) means that the $Z$-values are calculated for earthquakes with a magnitude equal to, or less than, the values indicated on the axis scale.

Therefore, we conclude that the pair of Anomalies 1 and 2 is significant statistically.

\section{Discussions}

\subsection{Effect of a declustering process}

In this study, clustered events such as aftershocks and earthquake swarms are not removed. In this section, we apply a declustering process to the earthquake catalog used in this study, and show that this has no effect on the results obtained. First, the study area is divided into six subareas: (Area name, latitude range, longitude range, the number of earthquakes in the area $)=\left(\right.$ Area $1,34.5-36^{\circ} \mathrm{N}, 139-$ $140^{\circ} \mathrm{E}, 97$ ), (Area $2,36-37.5^{\circ} \mathrm{N}, 139-140^{\circ} \mathrm{E}, 101$ ), (Area $3,34.5-36^{\circ} \mathrm{N}, 140-141^{\circ} \mathrm{E}, 302$ ), (Area $4,36-37.5^{\circ} \mathrm{N}, 140$ $\left.141^{\circ} \mathrm{E}, 232\right)$, (Area $\left.5,34.5-36^{\circ} \mathrm{N}, 141-142.5^{\circ} \mathrm{E}, 113\right)$, and (Area $6,36-37.5^{\circ} \mathrm{N}, 141-142.5^{\circ} \mathrm{E}, 352$ ). To test the hypothesis that the seismicity in each of the subareas is stationary Poissonian associated with time, we quantitatively evaluate the discrepancies between the observed frequency distribution and the expected Poissonian distribution by the $\chi^{2}$-test (e.g., Gardner and Knopoff, 1974; Wyss and Toya, 2000). Based on the results of the $\chi^{2}$-test for goodness of fit, we remove earthquake clusters so that the seismicity fulfills the hypothesis.

We show the case of Area 3 as an example. The number of earthquakes included in this area is $N_{q}=302$. The start date of the earthquake catalog is 1 January, 1996, and the end date is 31 December, 2007. Thus, the time length of the catalog is $T_{\text {cat }}=12$ years. The $T_{\text {cat }}$ is divided into $K=2400$ disjoint time intervals of length $T_{\text {cat }} / K=0.005$ years $(\sim 1.8$ days $)$. We estimate the averaged rate of events per interval $\lambda=N_{\text {eq }} / K=0.126$ (Gardner and Knopoff, 1974; Barani et al., 2007; Luen and Stark, 2012). We count the number of intervals including no earthquake, $\operatorname{Obs}(0)=$ 2144. Next, we count the number of intervals including one earthquake, $\operatorname{Obs}(1)=227$. In the same manner, we also $\operatorname{obtain} \operatorname{Obs}(2)=23, \operatorname{Obs}(3)=4, \operatorname{Obs}(4)=1, \operatorname{Obs}(5)=1$, $\operatorname{Obs}(6)=0, \operatorname{Obs}(7)=0$, and $\operatorname{Obs}(8)=1$. The $\operatorname{Obs}(c)$ $(c=0,1, \ldots, 8)$ forms the observed frequency distribution. The expected Poissonian distribution $\mathrm{Cal}(c)$ is calculated as $\mathrm{Cal}(c)=K e^{-\lambda} \lambda^{c} / c$ !. Then, the $\chi^{2}$ statistic is calculated as follows:

$$
\chi^{2}=\sum_{c=0}^{8} \frac{(\mathrm{Obs}(c)-\mathrm{Cal}(c))^{2}}{\operatorname{Cal}(c)}
$$

In this case, we obtain $\chi^{2}=126871.318$ with 7 degrees of freedom, and the hypothesis that the seismicity in Area 3 is a Poisson process is rejected significantly. The discrepancy between the observations and the calculations is mainly caused by $\operatorname{Obs}(8)=1$, which consists of a $M 5.4$ main shock and seven aftershocks on 16 August, 2007, around $\left(35.44^{\circ} \mathrm{N}, 140.54^{\circ} \mathrm{E}\right)$. Therefore, we remove all earthquakes included in $\operatorname{Obs}(8)$ except for the main shock, which is a declustering process based on the $\chi^{2}$-test. After removing the cluster, the $\chi^{2}$ statistic decreases to $\chi^{2}=0.871$ with 4 degrees of freedom, and then the hypothesis cannot be rejected with a $99 \%$ significant level. Since the seismicity in Area 3 is confirmed to be a Poisson process, more declustering is not necessary.

The results of the $\chi^{2}$-test in other areas are as follows: $\chi^{2}=1.654$ with 3 degrees of freedom in Area $1, \chi^{2}=$ 1.402 with 3 degrees of freedom in Area $2, \chi^{2}=0.001$ with 2 degrees of freedom in Area $4, \chi^{2}=1795205.845$ with 6 degrees of freedom in Area 5, and $\chi^{2}=38046.991$ with 7 degrees of freedom in Area 6. Declustering is not needed in Areas 1, 2, and 4. On the other hand, some clustered events should be removed in Areas 5 and 6 so that the seismicity fulfills the Poisonnian hypothesis. After the declustering process, the $\chi^{2}$ statistic decreases to $\chi^{2}=0.010$ with 1 degree of freedom for Area 5, and $\chi^{2}=0.060$ with 3 degrees of freedom for Area 6.

As a result of applying the declustering process, 39 earthquakes are removed in the whole area, which is only $3 \%$ of the non-declustered catalog. We find that the Anomalies 1 to 3 are clearly imaged even if the declustered catalog is used. Therefore, we conclude that the declustering process has no effect on the results obtained in this study.

\subsection{A long-term slow slip event (LSSE) model}

Whereas the seismicity rate changes we observe may be explained by various models, our preferred explanation is that it is caused by a long-term slow slip event (LSSE) rather than, for example, a dilatancy model or an earthquake interaction model. For an interpretation of the foreshock sequence (Hirose et al., 2011) prior to the 2011 Tohoku earthquake ( $M 9.0)$, there are two conflicting hypotheses: a slow slip event model (Ando and Imanishi, 2011; Kato et 
A1

A2

A3
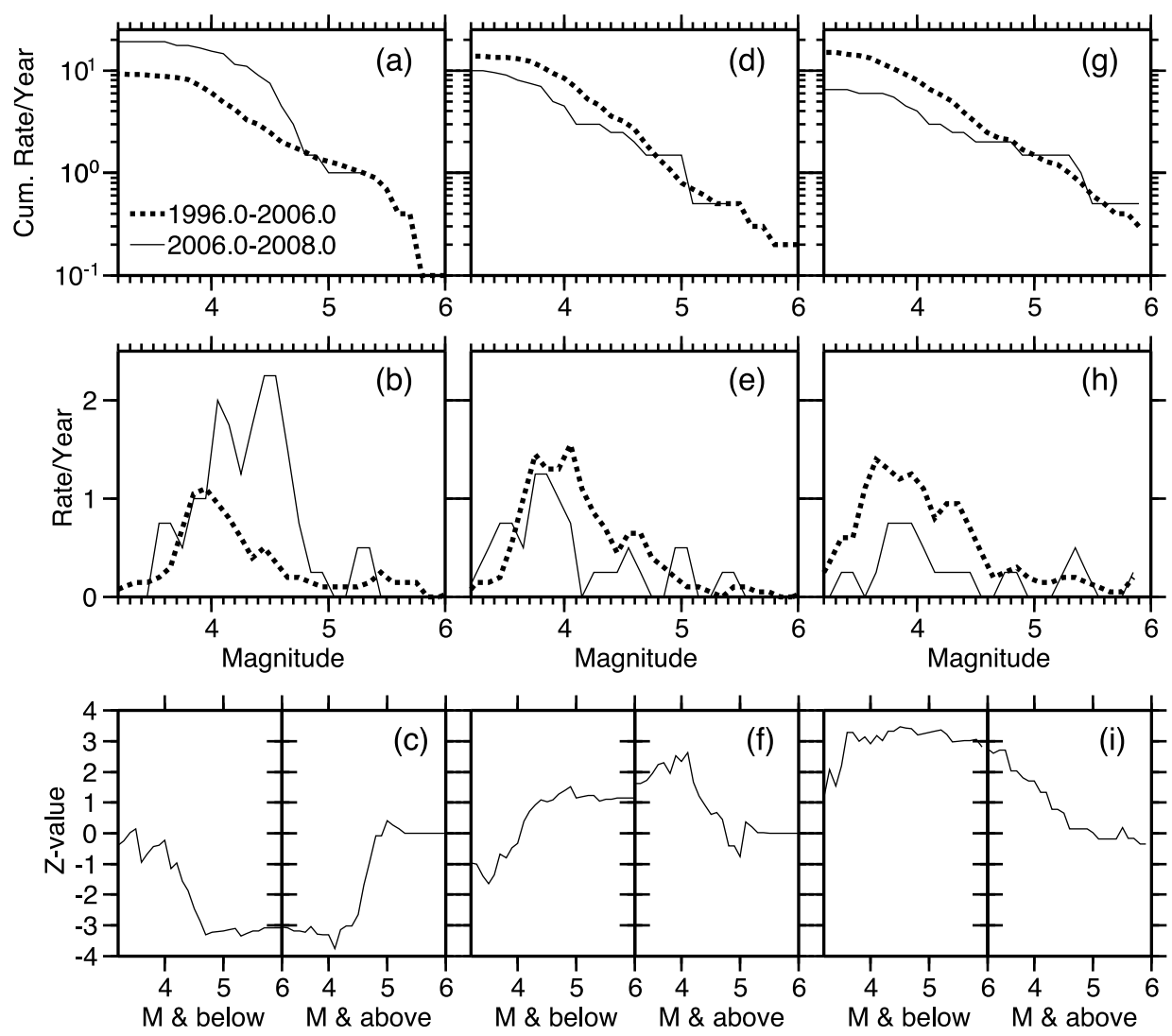

Fig. 9. Magnitude signatures for the three anomaly areas: A1, A2, and A3. Broken and bold lines indicate the normal period and the anomalous period, respectively. (a) Plot of magnitude vs. cumulative number. (b) Plot of magnitude vs. frequency. (c) Plot of magnitude vs. $Z$-value. The label "M $\&$ below" on the horizontal axis in (c) means that the $Z$-values are calculated for earthquakes with a magnitude equal to, or less than, the values indicated on the axis scale.
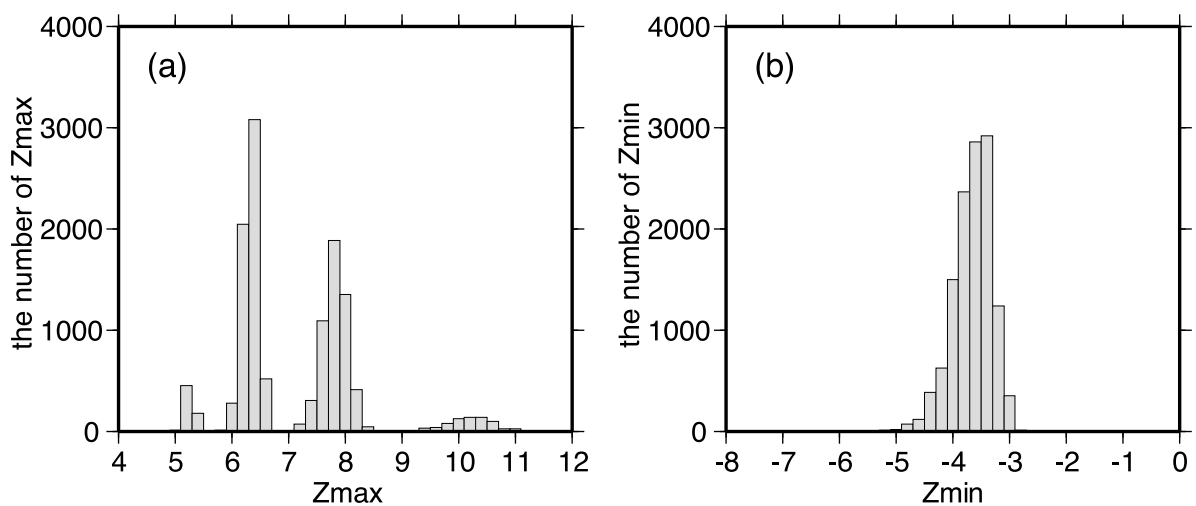

Fig. 10. Numerical simulations assuming that earthquakes occur randomly in space and time. 12,500 synthetic earthquake catalogs are produced by UNIX commands. (a) and (b) distribution of $Z_{\max }$ and $Z_{\min }$, respectively, obtained by the same ZMAP analysis that is applied to the real earthquake catalog.

al., 2012) and an earthquake interaction model (Marsan and Enescu, 2012; Gusman et al., 2013). The earthquake interaction model does not need to invoke aseismic transients for explaining the foreshock sequence.

Although it is difficult to say which hypothesis is correct, we propose the LSSE model in this study which causes the seismicity rate changes, based on the following two reasons. First, as is shown later, the fault plane of the LSSE is assumed to be on the upper surface of the subducting PA plate. In this area, Nakajima and Hasegawa (2010) found the outstanding low-velocity anomaly of an $S$-wave, and interpreted that this is evidence of the serpentinization of the mantle portion of the $\mathrm{PH}$ plate, which contacts with the upper surface of the PA plate. Kodaira et al. (2004) proposed the hypothesis that the LSSE in the Tokai district was caused by a high pore-fluid pressure in the oceanic crust of the subducting PH plate, which was derived from a high Poisson's ratio detected by seismic tomography. Figure 11(a) shows the Poisson's ratio along a curved surface $5 \mathrm{~km}$ below the upper surface of the subducting PA plate (Naka- 


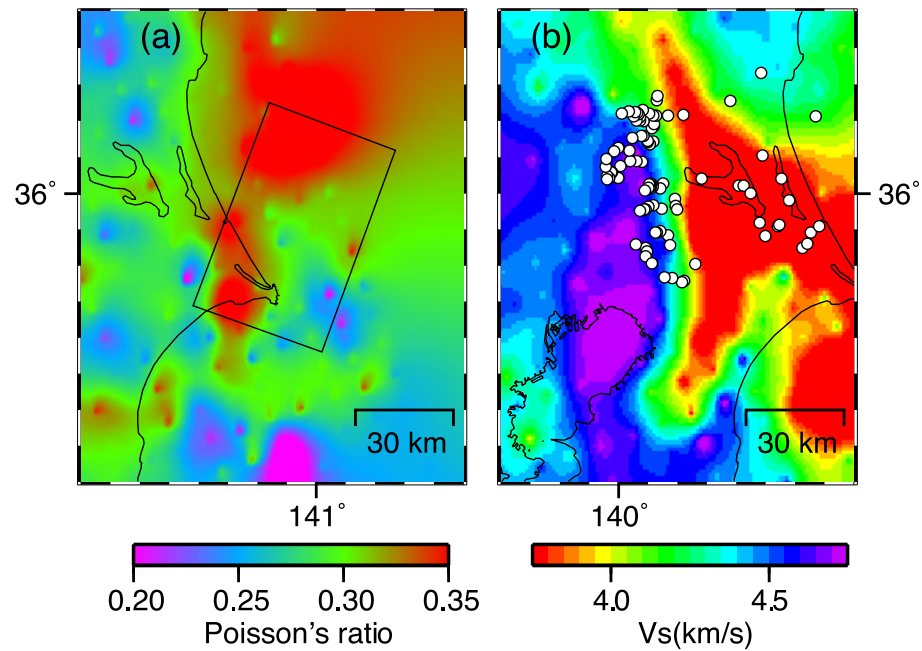

Fig. 11. (a) Poisson's ratio $5 \mathrm{~km}$ below the upper boundary of the PA plate determined by Nakajima and Hasegawa (2010). A rectangle indicates the fault plane of an LSSE assumed in this study. (b) $S$-wave velocity along a curved surface located $10 \mathrm{~km}$ above the upper boundary of the Pacific plate (Nakajima and Hasegawa, 2010), and the earthquakes (white dots) within the activation anomaly volume, which are the same as blue dots plotted in Fig. 7(a).

(a) activation area



(d) activation area

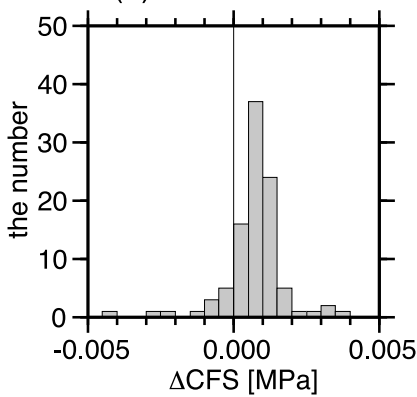

(b) quiescence area

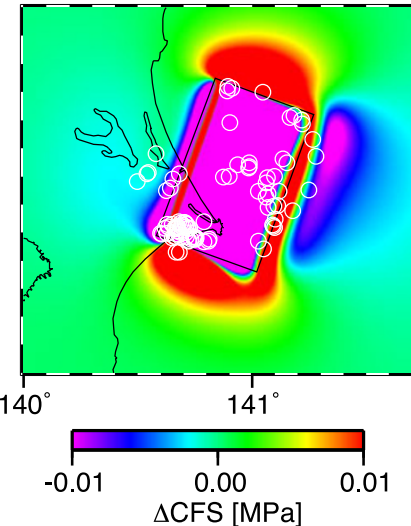

(e) quiescence area



(c) the 2008 main shock area

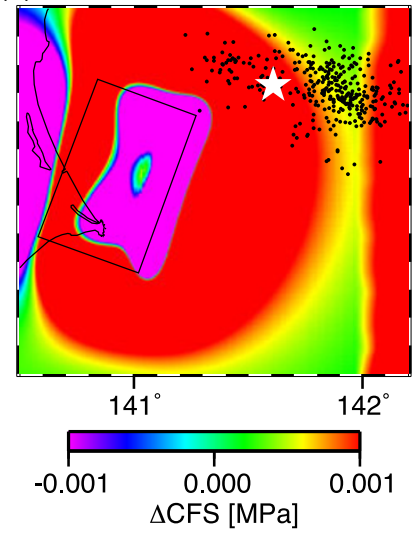

$\triangle \mathrm{CFS}[\mathrm{MPa}]$

Fig. 12. Change in Coulomb failure stress $(\triangle \mathrm{CFS})$ in, and around, the quiescence and the activation anomalies. The rectangle is a projection onto the ground surface of the assumed fault plane of the LSSE model. (a) $\triangle \mathrm{CFS}$ at a depth of $60 \mathrm{~km}$. Open black circles indicate the epicenters at depths from 50 to $90 \mathrm{~km}$ in the volume of Anomaly 1 . The focal mechanism of receiver earthquakes is assumed to be strike $=270^{\circ}$, dip $=20^{\circ}$, and rake $=$ $110^{\circ}$. (b) $\triangle \mathrm{CFS}$ at a depth of $40 \mathrm{~km}$. Open white circles indicate the epicenters at depths from 0 to $50 \mathrm{~km}$ in the volume of Anomaly 2 . The focal mechanism of receiver earthquakes is assumed to be strike $=200^{\circ}$, dip $=20^{\circ}$, and rake $=100^{\circ}$. (c) $\Delta$ CFS at a depth of $20 \mathrm{~km}$. The white star and black dots show the hypocenter of the 2008 Ibaraki-oki main shock and its aftershocks determined by JMA, respectively. The focal mechanism of receiver earthquakes is assumed to be the same as the 2008 Ibaraki-oki main shock determined by Nagoya University $(2008):$ strike $=205^{\circ}$, dip $=$ $17^{\circ}$, and slip $=87^{\circ}$. (d) and (e) are $\triangle \mathrm{CFS}$ histograms for earthquakes in the activation and the quiescence areas, respectively. $\Delta \mathrm{CFSs}$ are calculated based on the focal mechanisms determined by NIED for each earthquake.

jima and Hasegawa, 2010). Ozawa et al. (2012) found that there are two outstanding areas of afterslip for the first month after the 2011 Tohoku earthquake: One is located at the Iwate to Miyagi coastal area, and the other is located off coast of the Chiba prefecture (see figure 10(a) in Ozawa et al., 2012). The afterslip areas might be in a physical condition which easily causes an aseismic slow slip. Therefore, we assume a fault plane of the LSSE at the area off the 
coast of Chiba prefecture, where Ozawa et al. (2012) found the afterslip.

On the assumption that an LSSE causes between the PA plate and the overriding plate, we assume a simple rectangular fault model. The fault size of the LSSE is $66 \mathrm{~km} \times$ $41 \mathrm{~km}$ so that it includes the epicenters within the Anomaly 2 volume. The strike, the dip, and the rake angles are assumed to be $200^{\circ}, 18^{\circ}$, and $+123^{\circ}$, respectively, which are the same as those of the subducting PA plate in this region. The slip is assumed to be $9.5 \mathrm{~cm}$ in the period between 1 July, 2005, and 31 December, 2007, for 2.5 years. Thus, if the rigidity is $3.0 \times 10^{10} \mathrm{~N} / \mathrm{m}^{2}$, the seismic moment is $M_{0}=7.7 \times 10^{18} \mathrm{~N} \mathrm{~m}\left(M_{\mathrm{w}}=6.5\right)$. The fault motion, 9.5 $\mathrm{cm}$ per 2.5 years, is assumed so that GEONET is not able to detect the surface deformation.

\section{3 $\Delta$ CFS caused by the LSSE model}

To test the LSSE model, the Coulomb failure stress change $(\triangle \mathrm{CFS})$ in and around Anomalies 1 and 2 is calculated. In its simplest form, $\triangle \mathrm{CFS}$ is defined by:

$$
\Delta \mathrm{CFS}=\Delta \tau+\mu \Delta \sigma_{n},
$$

where $\Delta \tau$ is the shear stress change on a fault and $\Delta \sigma_{n}$ is the normal stress change. $\mu$ is the effective friction coefficient (with a range of $0-1$ ). Failure is promoted if $\triangle \mathrm{CFS}$ is positive, and failure is suppressed if $\triangle \mathrm{CFS}$ is negative (e.g., Stein and Lisowski, 1983; Stein, 1999). $\Delta \tau$ and $\Delta \sigma_{n}$ are calculated in an elastic half-space, based on Okada (1992), assuming that the rigidity is $3.0 \times 10^{10} \mathrm{~N} / \mathrm{m}^{2}$ and the Poisson's ratio is 0.25 . The effective friction coefficient is taken to be 0.4 . The fault parameters are assumed to be the same as those obtained in the previous section. In this study, the receivers are the earthquakes included in the volumes of Anomalies 1 and 2. The National Research Institute for Earth Science and Disaster Prevention (NIED) publishes a catalog of CMT solutions (Fukuyama et al., 1998) determined by a broadband seismograph network, F-net. Based on the NIED catalog, a plate-boundary type of focal mechanism is dominant in the volume of Anomaly 1 . Although the fault parameters fluctuate slightly, almost all earthquakes occur on the upper boundary of the subducting $\mathrm{PH}$ plate. Thus, the representative fault parameters for the receivers in the Anomaly 1 area are: strike $=270^{\circ}$, dip $=20^{\circ}$, and rake $=110^{\circ}$. On the other hand, almost all earthquakes occur on the upper boundary of the subducting PA plate in the volume of Anomaly 2. Thus, the representative fault parameters for the receivers in the Anomaly 2 area are: strike $=200^{\circ}$, dip $=20^{\circ}$, and rake $=100^{\circ}$.

The resultant $\triangle$ CFS patterns are shown in Figs. 12(a-c). In the volumes of Anomalies 1 and 2, $\triangle \mathrm{CFS}$ is positive and negative, respectively. This is consistent with the seismic activation in the Anomaly 1 area and the quiescence in the Anomaly 2 area. We also calculate $\triangle \mathrm{CFS}$ for each earthquake in the Anomalies 1 and 2 areas by using each focal mechanism solution determined by NIED (Figs. 12(d, e)). $\triangle \mathrm{CFS}$ for 2.5 years ranges from 0.0 to $+0.002 \mathrm{MPa}$ in the activation area and from -0.15 to $0.0 \mathrm{MPa}$ in the quiescence area. The hypocenter, i.e., the rupture initiation point of the 2008 Ibaraki-oki main shock, is located in an area with a positive $\triangle \mathrm{CFS}$ of $+0.001 \mathrm{MPa}$. An increase of $0.001 \mathrm{MPa}$ is not large but is a positive value, suggesting that the LSSE may have promoted the rupture initiation of the 2008 Ibaraki-oki main shock.

The $\triangle$ CFS estimations depend on the assumptions made for the position and setting of the "source" and "receiver" faults, as well as the effective friction coefficient $(\mu)$ value. Reliable estimations require some quantification of the uncertainties involved by these various assumptions (e.g., Parsons et al., 2008; Aoi et al., 2010). We have discussed above the stress change variations due to changes in the "receiver" focal mechanism. In addition, since $\mu=0.4$ is assumed for the main computations, we have also checked the stress change dependence on the $\mu$ coefficient. We found that the absolute values of $\triangle \mathrm{CFS}$ vary by a factor of 3 to 4 if $\mu$ changes from 0.0 to 1.0 . Thus, even if $\mu$ changes from 0.0 to 1.0 in this study, the absolute value of $\triangle \mathrm{CFS}$ does not vary by an order. In the areas of positive $\triangle \mathrm{CFS}$, the values are $\sim 0.0005 \mathrm{MPa}$ if $\mu=0.0, \sim 0.002 \mathrm{MPa}$ if $\mu=1.0$. In the areas of negative $\Delta \mathrm{CFS}$, the value is in the order of 0.01 MPa even if $\mu$ changes from 0.0 to 1.0 .

\subsection{Does the small positive $\Delta$ CFS trigger earthquakes?}

As described in Section 4.3, the increase in $\triangle \mathrm{CFS}$ in the activation area is in the order of $0.001 \mathrm{MPa}$, which is approximately 10 times smaller than the smallest stress level $(0.01 \mathrm{MPa})$ that has been reported for the triggering of nearby earthquakes (Anderson and Johnson, 1999). The shear stress in the order of $0.001 \mathrm{MPa}$ is almost the same as that produced by the Earth's tide. Since there is no clear correlation between tidal stress and seismicity (Emter, 1997), many researchers believe that static stress changes of the same magnitude are not expected to trigger earthquakes. On the other hand, Ziv and Rubin (2000) reported that, in central California, static stress changes in the order of 0.001 MPa have a noticeable triggering effect. While tidal stresses are periodic, stress changes due to the LSSE continues for a long time. As the duration over which a stress change acts increases, its effect on the time of a future earthquake becomes larger (Dieterich, 1994). This is a candidate to explain why $\triangle \mathrm{CFS}$ as small as the Earth's tide causes an increase in seismicity.

There is another possibility. Tidal stress perturbations can trigger earthquakes only when a region reaches a critical state for failure in the case of large/great earthquakes. Tidal triggering was detected only in several to ten years preceding the 2004 Sumatra earthquake $\left(M_{\mathrm{w}} 9.1\right)$ and vanished afterwards (Tanaka, 2010). The same observation was reported prior to the 2011 Tohoku-oki earthquake $\left(M_{\mathrm{w}} 9.0\right)$ (Tanaka, 2012). Therefore, if the activation area detected in the present study had been close to failure, small $\triangle \mathrm{CFS}$ can trigger some earthquakes and, thus, the seismicity increases. Nakajima and Hasegawa (2010) obtained detailed images of $P$ - and $S$-wave velocity structures beneath the Kanto district, and found the serpentine boundary which is the western boundary of the serpentinized mantle in the PH plate, and $P$ - and $S$-wave velocities varied by $15-20 \%$ across it over a short distance of $\sim 10 \mathrm{~km}$. They presented a hypothesis that the $\mathrm{PH}$ plate is divided into eastern and western parts by the serpentine boundary: the eastern part is the metamorphosed (serpentinized) mantle and the western part is the unmetamorphosed (dry) mantle, and the relative movement between the two parts is a right-lateral motion. 
In fact, at least two large earthquakes with $M \sim 7$ occurred along the serpentine boundary, the 1921 Ibaraki earthquake (M 7.0) and the 1987 Chiba earthquake (M 6.7), which probably ruptured asperities along the serpentine boundary. Nakajima and Hasegawa (2010) suggested that taking the deformation rate into account, a 1921-type earthquake would be expected to occur in the near future along the serpentine boundary. We find that the hypocenters within the volume of the activation area (Anomaly 1) appear to be located along the serpentine boundary (Fig. 11(b)). If this area corresponds to an asperity that reaches a critical state for failure, small positive $\triangle \mathrm{CFS}$ can cause an increase in long-term seismicity.

\section{Conclusions}

The earthquake catalog used in this study is of unusually high quality from the point of view of homogeneous reporting in the Kanto area (Fig. 1). In general, earthquake catalogs are not homogeneous temporally and spatially (Habermann, 1987, 1991). Therefore, as described in Section 2, the catalog are carefully re-examined before performing a statistical analysis of long-term seismicity changes. As a result, we have found a pair of the seismic quiescence and activation anomalies beneath the Kanto district, and have confirmed that they are significant anomalies statistically. A possible physical model to explain the seismic quiescence and activation simultaneously might be an LSSE model on the upper boundary of the subducting PA plate. We show that the spatial pattern of $\triangle \mathrm{CFS}$ caused by the LSSE model matches qualitatively with that of the seismic anomalies. The LSSE fault plain is located at a high Poisson's ratio area, indicating that the dehydration reaction occurs in the oceanic crust of the subducting PA plate. This fact suggests that the LSSE seems to be a plausible model in the present study. For future studies, it is worth noting that a seismicity rate change might be an indicator of an LSSE, and an LSSE with a small displacement can be detected by a careful investigation of the seismicity rate.

Acknowledgments. We thank Stefan Wiemer for providing the ZMAP software, Junichi Nakajima for providing the tomography data, and two anonymous reviewers for valuable comments. GMTSYSTEM (Wessel and Smith, 1991) was used for data mapping. MICAP-G (Naito and Yoshikawa, 1999) was used to calculate changes in the Coulomb failure stress. Naoto Wada helped to produce the homogeneous earthquake catalog.

\section{References}

Anderson, G. and H. Johnson, A new statistical test for static stress triggering: Application to the 1987 Superstition Hills earthquake sequence, J. Geophys. Res., 104, 20,153-20,168, 1999.

Ando, R. and K. Imanishi, Possibility of $M_{\mathrm{w}} 9.0$ mainshock triggered by diffusional propagation of after-slip from $M_{\mathrm{w}} 7.3$ foreshock, Earth Planets Space, 63, 767-771, 2011.

Aoi, S., B. Enescu, W. Suzuki, Y. Asano, K. Obara, T. Kunugi, and K. Shiomi, Stress transfer in the Tokai subduction zone from the 2009 Suruga Bay earthquake in Japan, Nat. Geosci., 3, 496-500, doi:10.1038/ngeo885, 2010.

Barani, S., G. Ferretti, M. Massa, and D. Spallarossa, The waveform similarity approach to identify dependent events in instrumental seismic catalogues, Geophys. J. Int., 168, 100-108, 2007.

Cervelli, P., P. Segall, K. Johnson, M. Lisowski, and A. Miklius, Sudden aseismic fault slip on the south flank of Kilauea volcano, Nature, $\mathbf{4 1 8}$, 108-108, 2002.
Dieterich, J., A constitutive law for rate of earthquake production and its application to earthquake clustering, J. Geophys. Res., 99, 2601-2618, 1994.

Dieterich, J., V. Cayol, and P. Okubo, The use of earthquake rate changes as a stressmeter at Kilauea volcano, Nature, 408, 457-460, 2000.

Dragert, H., K. Wang, and T. S. James, A silent slip event on the deeper Cascadia subduction interface, Science, 292, 1525-1528, 2001.

Emter, D., Tidal triggering of earthquakes and volcanic events, in Tidal Phenomena, edited by Wilhelm, H., W. Zurn, and H. G. Wenzel, Lect. Notes Earth Sci., vol. 66, pp. 293-309, Springer-Verlag, Berlin, 1997.

Fukuyama, E., S. Ishida, D. S. Dreger, and H. Kawai, Automated seismic moment tensor determination by using on-line broadband seismic waveforms, J. Seismol. Soc. Jpn, 51, 149-156, 1998 (in Japanese with English abstract).

Gardner, J. K. and L. Knopoff, Is the sequence of earthquakes in Southern California, with aftershocks removed, Poissonian?, Bull. Seismol. Soc. Am., 64, 1363-1367, 1974.

Gusman, A. R., M. Fukuoka, Y. Tanioka, and S.-i. Sakai, Effect of the largest foreshock $\left(\mathrm{M}_{\mathrm{w}} 7.3\right)$ on triggering the 2011 Tohoku earthquake $\left(\mathrm{M}_{\mathrm{w}}\right.$ 9.0), Geophys. Res. Lett., 40, doi:10.1002/grl.50153, 2013.

Habermann, R. E., Man-made changes of seismicity rates, Bull. Seismol. Soc. Am., 77, 141-157, 1987.

Habermann, R. E., Seismicity rate variations and systematic changes in magnitudes in teleseismic catalogs, Tectonophysics, 193, 277-289, 1991.

Habermann, R. E. and F. Creamer, Catalog errors and the M8 earthquake prediction algorithm, Bull. Seismol. Soc. Am., 84, 1551-1559, 1994.

Hirata, N. and M. Matsu'ura, Maximum-likelihood estimation of hypocenter with origin time eliminated using nonlinear inversion technique, Phys. Earth Planet. Inter., 47, 50-61, 1987.

Hirose, F., K. Miyaoka, N. Hayashimoto, T. Yamazaki, and M. Nakamura, Outline of the 2011 off the Pacific coast of Tohoku Earthquake ( $M_{\mathrm{w}}$ 9.0)-Seismicity: foreshocks, mainshock, aftershocks, and induced activity_, Earth Planets Space, 63, 513-518, 2011.

Hirose, H. and K. Obara, Repeating short- and long-term slow slip events with deep tremor activity around the Bungo channel region, southwest Japan, Earth Planets Space, 57, 961-972, 2005.

Hirose, H., H. Kimura, B. Enescu, and S. Aoi, Recurrent slow slip event likely hastened by the 2011 Tohoku earthquake, Proc. Natl. Acad. Sci. USA, 109, 15157-15161, 2012.

Kato, A., K. Obara, T. Igarashi, H. Tsuruoka, S. Nakagawa, and N. Hirata, Propagation of slow slip leading up to the 2011 Mw9.0 Tohoku-Oki earthquake, Science, 335, 705-708, 2012.

Katsumata, K., Precursory seismic quiescence before the $\mathrm{Mw}=8.3$ Tokachi-oki, Japan, earthquake on 26 September 2003 revealed by a re-examined earthquake catalog, J. Geophys. Res., 116, B10307, doi:10.1029/2010JB007964, 2011.

Kobayashi, T. and M. Hashimoto, Change of strain rate and seismicity in the Chubu district, central Japan, associated with a Tokai slow event, Earth Planets Space, 59, 351-361, 2007.

Kodaira, S., T. Iidaka, A. Kato, J. Park, T. Iwasaki, and Y. Kaneda, High pore fluid pressure may cause silent slip in the Nankai trough, Science, 304, 1295-1298, 2004.

Llenos, A. L. and J. J. McGuire, Detecting aseismic strain transients from seismicity data, J. Geophys. Res., 116, B06305, doi:10.1029/2010JB007537, 2011.

Luen, B. and P. B. Stark, Poisson test of declustering catalogues, Geophys. J. Int., 189, 691-700, 2012.

Marsan, D. and B. Enescu, Modeling the foreshock sequence prior to the $2011 \mathrm{M}_{\mathrm{w}} 9.0$ Tohoku Japan earthquake, J. Geophys. Res., 117, B06316, doi:10.1029/2011JB009039, 2012.

Matsumura, S., Seismic activity changes progressing simultaneously with slow-slip in the Tokai area, Tectonophysics, 417, 5-15, 2006.

Matsumura, S., Discrimination of a preparatory stage leading to M7 characteristic earthquakes off Ibaraki Prefecture, Japan, J. Geophys. Res., 115, B01301, doi:10.1029/2009JB006584, 2010.

Nagoya University, Source process of off-Ibaraki earthquake on May 8 , 2008 (Mj6.4, 7.0), Rep. Coord. Comm. Earthq. Predict., 80, 108-110, 2008.

Naito, H. and S. Yoshikawa, A program to assist crustal deformation analysis, J. Seismol. Soc. Jpn, 52, 101-103, 1999 (in Japanese).

Nakajima, J. and A. Hasegawa, Cause of $\mathrm{M} \sim 7$ intraslab earthquakes beneath the Tokyo metropolitan area, Japan: Possible evidence for a vertical tear at the easternmost portion of the Philippine Sea slab, $J$. Geophys. Res., 115, B04301, doi:10.1029/2009JB006863, 2010.

Obara, K., H. Hirose, F. Yamamizu, and K. Kasahara, Episodic slow slip 
events accompanied by non-volcanic tremors in southwest Japan subduction zone, Geophys. Res. Lett., 31, L23602, 2004.

Ohta, Y., J. T. Freymueller, S. Hreinsdottir, and H. Suito, A large slow slip event and the depth of the seismogenic zone in the south central Alaska subduction zone, Earth Planet. Sci. Lett., 247, 108-116, 2006.

Okada, Y., Internal deformation due to shear and tensile faults in a halfspace, Bull. Seismol. Soc. Am., 82, 1018-1040, 1992.

Outerbridge, K. C., T. H. Dixon, S. Y. Schwartz, J. I. Walter, M. Protti, V. Gonzalez, J. Biggs, M. Thorwart, and W. Rabbel, A tremor and slip event on the Cocos-Caribbean subduction zone as measured by a global positioning system (GPS) and seismic network on the Nicoya Peninsula, Costa Rica, J. Geophys. Res., 115, B10408, doi:10.1029/2009JB006845, 2010.

Ozawa, S., M. Murakami, M. Kaidzu, T. Tada, T. Sagiya, Y. Hatanaka, H. Yarai, and T. Nishimura, 2002. Detection and monitoring of ongoing aseismic slip in the Tokai region, central Japan, Science, 298, 10091012, 2002.

Ozawa, S., H. Suito, and M. Tobita, Occurrence of quasi-periodic slow-slip off the east coast of the Boso peninsula, Central Japan, Earth Planets Space, 59, 1241-1245, 2007.

Ozawa, S., T. Nishimura, H. Munekane, H. Suito, T. Kobayashi, M. Tobita, and T. Imakiire, Preceding, coseismic, and postseismic slips of the 2011 Tohoku earthquake, Japan, J. Geophys. Res., 117, B07404, doi:10.1029/2011JB009120, 2012.

Parsons, T., C. Ji, and E. Kirby, Stress changes from the 2008 Wenchuan earthquake and increased hazard in the Sichuan basin, Nature, 454, 509$510,2008$.

Seno, T. and T. Sakurai, Can the Okhotsk plate be discriminated from the North American plate?, J. Geophys. Res., 101, 11305-11315, 1996.

Seno, T., S. Stein, and A. E. Gripp, A model for the motion of the Philippine Sea Plate consistent with NUVEL-1 and geological data, J. Geophys. Res., 98, 17941-17948, 1993.

Stein, R. S., The role of stress transfer in earthquake occurrence, Nature, 402, 605-609, 1999.

Stein, R. S. and M. Lisowski, The 1979 Homestead Valley earthquake sequence, California: control of aftershocks and postseismic deformation, J. Geophys. Res., 88, 6477-6490, 1983.

Suito, H., T. Nishimura, M. Tobita, T. Imakiire, and S. Ozawa, Interplate fault slip along the Japan Trench before the occurrence of the 2011 off the Pacific coast of Tohoku Earthquake as inferred from GPS data, Earth Planets Space, 63, 615-619, doi:10.5047/eps.2011.06.053, 2011.

Tanaka, S., Tidal triggering of earthquakes precursory to the recent Sumatra megathrust earthquakes of 26 December $2004\left(\mathrm{M}_{\mathrm{w}} 9.0\right)$, 28 March $2005\left(\mathrm{M}_{\mathrm{w}} 8.6\right)$, and 12 September $2007\left(\mathrm{M}_{\mathrm{w}} 8.5\right)$, Geophys. Res. Lett., 37, L02301, doi:10.1029/2009GL041581, 2010.

Tanaka, S., Tidal triggering of earthquakes prior to the 2011 Tohoku-Oki earthquake $\left(\mathrm{M}_{\mathrm{w}} 9.1\right)$, Geophys. Res. Lett., 39, L00G26,
doi:10.1029/2012GL051179, 2012.

Toda, S. and S. Matsumura, Spatio-temporal stress states estimated from seismicity rate changes in the Tokai region, central Japan, Tectonophysics, 417, 53-68, 2006.

Utsu, T., Representation and analysis of the earthquake size distribution: a historical review and some new approaches, Pure Appl. Geophys, 155, 509-535, 1999.

Wallace, L. M. and J. Beavan, A large slow slip event on the central Hikurangi subduction interface beneath the Manawatu region, North Islands, New Zealand, Geophys. Res. Lett., 33, L11301, doi:10.1029/2006GL026009, 2006.

Watanabe, H., Determination of earthquake magnitude at regional distance in and near Japan, J. Seismol. Soc. Jpn, 32, 281-296, 1971 (in Japanese).

Wessel, P. and W. H. F. Smith, Free software helps map and display data, Eos Trans. AGU, 72, 445-446, 1991.

Wiemer, S., Analysis of seismicity: new technique and case studies, Dissertation thesis (University of Alaska, Fairbanks, Alaska 1996), 151 pp, 1996.

Wiemer, S. and M. Wyss, Seismic quiescence before the Landers (M=7.5) and Big Bare (M=6.5) 1992 earthquakes, Bull. Seismol. Soc. Am., 84, 900-916, 1994.

Wiemer, S. and M. Wyss, Minimum magnitude of completeness in earthquake catalogs: examples from Alaska, the western United States, and Japan, Bull. Seismol. Soc. Am., 90, 859-869, 2000.

Wyss, M. and A. H. Martirosyan, Seismic quiescence before the M7, 1988, Spitak earthquake, Armenia, Geophys. J. Int., 134, 329-340, 1998.

Wyss, M. and Y. Toya, Is background seismicity produced at a stationary Poissonian rate?, Bull. Seismol. Soc. Am., 90, 1174-1187, 2000.

Wyss, M., K. Shimazaki, and T. Urabe, Quantitative mapping of a precursory quiescence to the Izu-Oshima $1990(\mathrm{M}=6.5)$ earthquake, Japan, Geophys. J. Int., 127, 735-743, 1996.

Yoshioka, S., T. Mikumob, V. Kostoglodov, K. M. Larson, A. R. Lowryd, and S. K. Singh, Interplate coupling and a recent aseismic slow slip event in the Guerrero seismic gap of the Mexican subduction zone, as deduced from GPS data inversion using a Bayesian information criterion, Phys. Earth Planet. Inter., 146, 513-530, 2004.

Zhuang, J., Y. Ogata, and D. Vere-Jones, Stochastic declustering of spacetime earthquake occurrences, J. Am. Stat. Assoc., 97, 369-380, 2002.

Ziv, A. and A. M. Rubin, Static stress transfer and earthquake triggering: No lower threshold insight?, J. Geophys. Res., 105, 13,631-13,642, 2000.

Zuniga, F. R. and S. Wiemer, Patterns: Are they always related to natural causes?, Pure Appl. Geophys., 155, 713-726, 1999.

K. Katsumata (e-mail: kkatsu@mail.sci.hokudai.ac.jp) and S. Sakai 